\title{
Diffusion tensor imaging: a smart move to olfactory pathway imaging; comparative study of chronic sinonasal polyposis patients and normal control
}

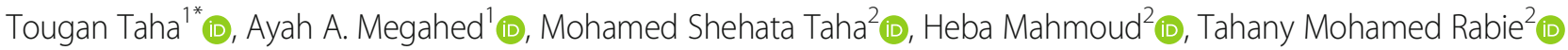
and Anas Mohamed Askora²

\begin{abstract}
Background: Olfaction is critically important for a good quality of life and incorporated in many physiological domains such as attention, emotion, memory, and airflow motor control. Olfactory researches have been expanded in the last decade due to close relation between the olfactory disorders and different brain diseases. Diagnosis of anosmia and hyposmia are based on history, smell tests, and physical examination which rely on the patient's response without an objective measure of impairment. This study assessed the value of volumetry and DTI parameters as objective measurements for olfactory dysfunction.

Fourteen patients with chronic sinonasal polyposis for at least 6 months were included in this study; all of them underwent tailored MRI examination including volumetry and DTI for olfactory bulbs and tracts. The results were compared to the same number of age and sex-matched healthy control group.
\end{abstract}

Results: The study results showed that olfactory bulb and tract (OB/T) volume, FA and ADC could distinguish between patients and healthy controls. Statistically significant differences were noticed between the FA \& ADC values of patient and control groups $(p<0.05)$ and a highly significant one was noticed as regarding the OT volume $(p<0.001)$.

Conclusion: MR volumetry and DTI parameters can be used as objective measurements for the olfactory dysfunction for patients with chronic sinonasal polyposis.

\section{Background}

Although olfaction is critically important for a good quality of life, personal safety, and nutritional status, the sense of smell is substantially underlooked [1]. The prevalence of olfactory disorders is quite high in population-based studies in which odor identification has been assessed. In a Swedish study, 19\% of the adult population was found to have some kind of dysfunction in the sense of olfaction [2]. Many factors influence the normal ability to smell. In patients presenting in otorhinolaryngological clinics, approximately $70 \%$ of all patients presenting with chronic hyposmia or anosmia

\footnotetext{
* Correspondence: toganwafi@yahoo.com

'Department of Radiology, Ain Shams University, Cairo, Egypt

Full list of author information is available at the end of the article
}

attribute that to sinonasal causes (of which, polyposis account for $14 \%$ to $30 \%$ ) [3-6], $10 \%$ are due to postinfectious inflammation of the mucosa, $1 \%$ have congenital anosmia, while the rest have a central cause for their anosmia (i.e., trauma; tumors; toxicity; or psychiatric, neurodegenerative, or another neurologic etiology) $[7,8]$. Correct assessment of the cause of olfactory impairment is important to determine which patients may benefit from therapy. It helps in the counseling of patients $[4,9,10]$. Conservative therapy with corticosteroids as well as surgical therapy have been proven to be effective in the treatment of sinonasal disease-related olfactory disorders but not non-sinonasal disease [11, 12]. Olfactory research has expanded rapidly over the last two decades, owing to the close relationship between anosmia and brain disease. Hyposmia and anosmia were 
identified as a prodromal symptom of Parkinson's disease (PD), as strong predictors of cognitive decline in Alzheimer's disease, and have been found to be closely related to depression [13-18]. Clinicians diagnose anosmia through history, physical examination, and smell tests [19] which depend entirely on patient responses. The available smell identification test may enable us to identify and diagnose olfactory dysfunction, but it does delineate central from peripheral causes.

Recently, efforts have been made to use neuroimaging of the olfactory tract and bulbs to refine the diagnosis of olfactory dysfunction. The measurement of olfactory bulb and tract $(\mathrm{OB} / \mathrm{T})$ by planimetric manual contouring on magnetic resonance imaging (MRI) correlated well with olfactory function $[20,21]$. However, these thin structures are difficult to measure with significant variations among healthy individuals rendering its efficiency as a diagnostic tool limited $[4,5,22]$.

Diffusion tensor imaging (DTI) is a non-invasive technique that is gaining popularity since it enables the delineation of white matter tracts as well as their connectivity of different brain areas [23]. It has been integrated in the evaluation of cranial nerves including the olfactory nerve, which has been a matter of study in both the normal and abnormal populations [24].

DTI studies of individuals with Parkinson's disease revealed a correlation between reduced fractional anisotropy (FA) values in the olfactory bulb and anosmia [25, 26]. Recently, several studies pointed out the capacity of DTI parameters of revealing brain tissue damage in early clinical stages of neurodegenerative diseases [26-28].

To the best of our knowledge, this is the first work that compares $\mathrm{OB} / \mathrm{T}$ volume and DTI parameters in patients with sinonasal polyposis as opposed to healthy controls.

The aim of this study was to evaluate the effect of olfactory deprivation caused by sinonasal polyposis on olfactory bulb volume and tract integrity.

\section{Methods}

This prospective study was carried out between January 2016 and July 2017. The study was approved by the institutional ethical committee and an informed consent was taken from all participants.

Twenty-eight subjects were included in this study: 14 adult patients who had a history of chronic nasal obstruction for more than 6 months who were diagnosed clinically with bilateral allergic sinonasal polyposis (patient group) and 14 healthy adults-matched for age and sex-with no history of olfactory dysfunction or sinonasal problems (control group). Patients who underwent biopsy or surgery; were previously treated; and have sinonasal neoplastic lesions, neurological disorders, or diabetes were excluded. All participants had MRI with DTI.

\section{MR image acquisition}

The study was performed on A 1.5-T MR unit (Gyroscan Achieva; Philips Medical Systems, The Netherlands). A tailored protocol was performed by selecting sequences from routine MR of PNS protocol including axial and coronal T2 STIR with 3-mm slice thickness, small field of view (FOV) that extends from the nasal tip to the brainstem (coronal plane) and from the superior border of the frontal sinus to the lower lip (axial plane). Three-dimensional DRIVE was added in coronal plane with slice thickness $0.8 \mathrm{~mm}$, repetition time (TR) 12-15 s. echo time (TE) 6-7 s. matrix $384 \times$ 320 , and NEX 1 for accurate localization of the olfactory nerve (Figs. 1b, 2a and 3a).

DT imaging data were acquired by using a single-shot echoplanar imaging sequence with the sensitivity encoding or SENSE, parallel-imaging scheme (reduction factor, 2 ). The imaging matrix was $128 \times 128$, with an FOV of $220 \times 220 \mathrm{~mm}$. Transverse sections of $2.75-\mathrm{mm}$ thickness acquired parallel to the anterior commissural-posterior commissural line was taken to cover the entire hemisphere and brainstem without gaps. Diffusion weighting was encoded along 12 independent orientations, with $b$ value of $1000 \mathrm{~mm}^{2} / \mathrm{s}$. Other imaging parameters were as follows: $\mathrm{TE}=70 \mathrm{~ms}, \mathrm{TR}=6599-8280$ $\mathrm{ms}$, and number of acquisitions $=2$. Co-registered magnetization-prepared rapid gradient-echo (MPRAGE) images of the same resolution were recorded for anatomic guidance. The total imaging time for DTI was 7-9 min according to the section numbers, which was added to the routine MR imaging examinations.

\section{Data processing \\ DTI}

We transferred the diffusion tensor imaging data to an offline workstation (extended workspace "EWS"; Release 2.5.3.0; Dell, Round Rock, Tx); Pride software (Philips Medical Systems).

FA and apparent diffusion coefficient (ADC) were taken by using a multiple region-of-interest (ROI) approach, where our ROI was the olfactory bulbs and tract on either side from the point of appearance superior to the nasal mucosa, moving posteriorly till they are last visualized (Fig. 3c).

\section{Volumetry}

Volumetric measurements were performed using manual segmentation of the coronal slices through the $\mathrm{OB} / \mathrm{T}$ along their course on both sides separately using 3D T1/ DRIVE sequences (Figs. 1c and 3b). 

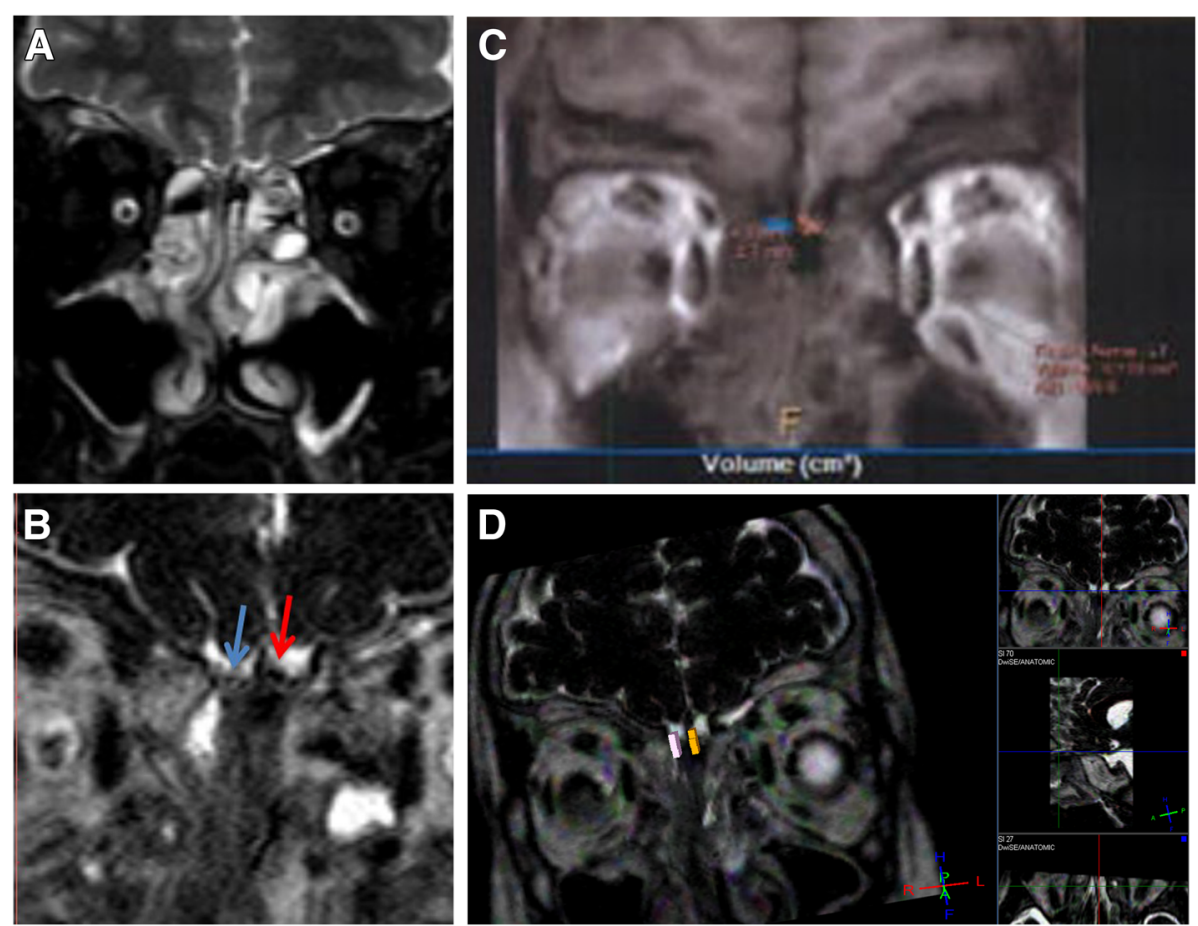

Fig. 1 Bilateral sinonasal polyposis with hyposmia. a Coronal T2 fat suppression sequence displaying bilateral ethmoidal polyposis and frontal sinus secretion obstruction. b 3D DRIVE sequence demonstrates smaller right OB (blue arrow) as compared to normal appearing left OB (red arrow) confirmed by (c) 3D T1WI volumetry; ROI was inserted on right bulb (blue) and left bulb (red). $\mathbf{d}$ Tractography for OT. The right tract has lower FA and higher ADC as compared to the normal left tract

\section{Statistical methods}

Data were analyzed using Stata ${ }^{\oplus}$ version 14.2 (Stata Corp LLC, College Station, TX, USA). Normality of numerical data distribution was examined using the Shapiro-Wilk test. Non-normally distributed numerical data were presented as median and interquartile range and intergroup differences were compared using the Wilcoxon rank sum test. Correlations were tested using the Spearman rank correlation. Receiver-operating characteristic (ROC) curve analysis was used to examine the diagnostic value of volumetry, FA, or ADC. The DeLong method was used to compare the areas under different ROC curve (AUC). $p$ value $<0.05$ was considered statistically significant.

\section{Results}

Fourteen patients were included in this study. Their age ranged from 27 to 45 years (median 34). There were 10 males $(71.4 \%)$ and 4 females (28.6\%); 11 patients $(78.6 \%)$ were anosmic and 3 patients (21.4\%) were hyposmic. The control group consisted of 14 healthy volunteers. There were 10 men (71.4\%) and 4 women (28.6\%), with an age range of 23 to 47 years (median 33).

Using the ROC curve analysis, OB/T volume, FA, and $\mathrm{ADC}$, with values of $\leq 0.054 \mathrm{~cm}^{3}, \leq 0.357$, and $\geq 1.417$ ( $\left.\times 10^{-3} \mathrm{~mm}^{2} / \mathrm{s}\right)$, respectively, were found to be a plausible cutoff point for discrimination between cases and controls (Table 1).

In the patient group, $\mathrm{OB} / \mathrm{T}$ volume measurements in both sides ranged from 0.0235 to $0.05025 \mathrm{~cm}^{3}$ (median $0.039 \mathrm{~cm}^{3}$ ). The FA value ranged from 0.27425 to 0.423 (median 0.3495), while ADC value $\left(\times 10^{-3} \mathrm{~mm}^{2} / \mathrm{s}\right)$ ranged from 0.98725 to 1.63 (median 1.0414).

In the control group, $\mathrm{OB} / \mathrm{T}$ volume measurements in both sides ranged from 0.09325 to $0.25125 \mathrm{~cm}^{3}$ (median $0.16 \mathrm{~cm}^{3}$ ). The FA value ranged from 0.35775 to 0.40225 (median 0.3865), while ADC value $\left(\times 10^{-3} \mathrm{~mm}^{2} / \mathrm{s}\right)$ ranged from 0.86925 to 1.299 (median 1.0595; Table 2).

The difference in $\mathrm{OB} / \mathrm{T}$ volume between patient and control groups was highly statistically significant $(p<$ 0.001 ), where the patient group had significantly smaller volumes than the control group (Fig. 4). Also, there were statistically significant differences in FA and ADC values between patients and control group ( $p$ values $=0.2144$ and 0.00438 , respectively).

\section{Discussion}

The sense of smell directs the intake of airborne agents into the human respiratory system and determines the flavor and palatableness of foods and beverages. Olfaction enhances the quality of life and yet olfactory disorders are neglected by the medical community [29]. 

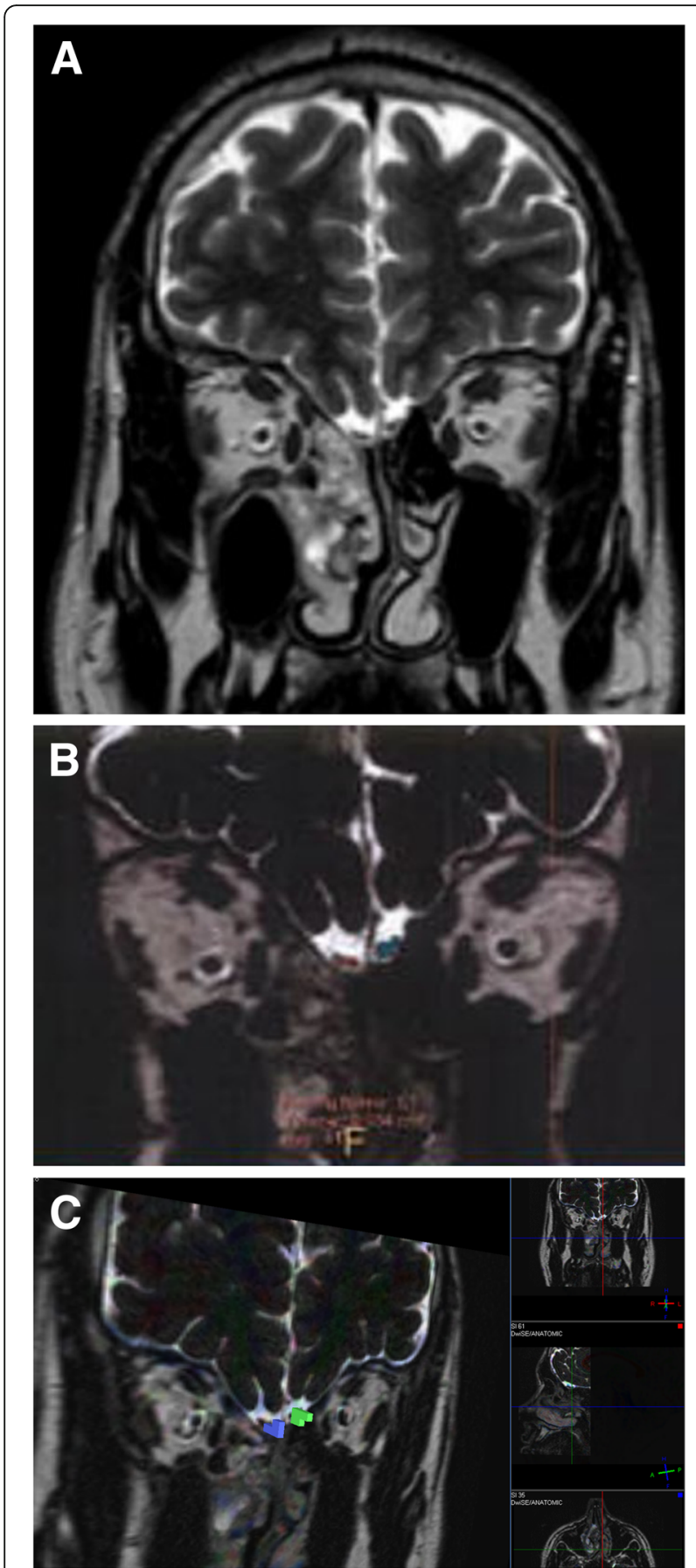

Fig. 2 Bilateral sinonasal polyposis with hyposmia. 3D DRIVE (a) for accurate localization of the OB (circle). MR volumetry (not shown) revealed largest left OB. MR tractography (b) revealed higher FA and lower ADC values for left tract (blue tract) keeping with more compact fibers. The parameters of the two tracts are still beyond the author's cutoff value

Many studies showed a statistically significant discrepancy in the $\mathrm{OB}$ volume between patients with bilateral sinonasal polyposis and healthy controls, in keeping with the findings revealed in experimental studies on animals,
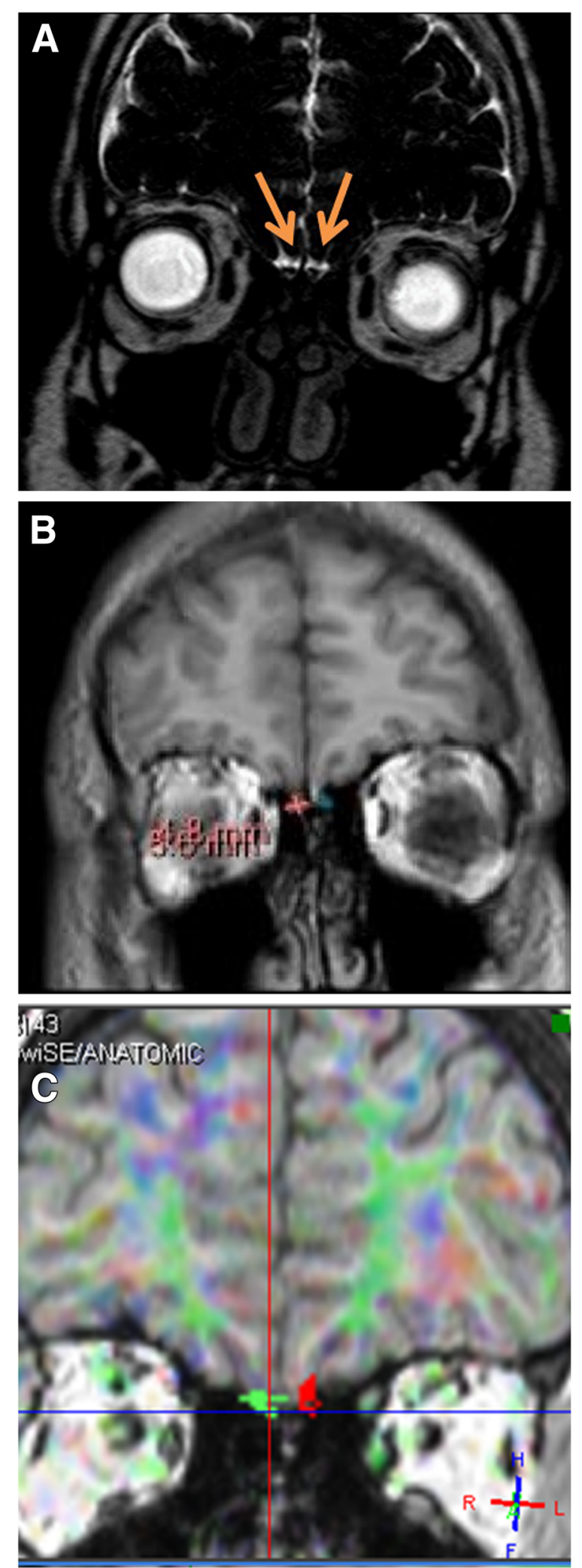

Fig. $3 \mathrm{OB} / \mathrm{T}$ in a normal volunteer. Arrows in 3D DRIVE (a), 3D T1WI volumetry (b), and MR tractography (c) 
Table 1 Receiver-operating characteristic (ROC) curve analysis for discrimination between cases and controls using the olfactory bulb volume, FA value, or ADC value

\begin{tabular}{|c|c|c|c|c|c|c|c|}
\hline & \multicolumn{7}{|c|}{ ROC parameters } \\
\hline & \multicolumn{2}{|l|}{ AUC } & \multirow[t]{2}{*}{$p$ value } & \multirow[t]{2}{*}{$J$ index } & \multirow[t]{2}{*}{ Cutoff criterion } & \multirow{2}{*}{$\begin{array}{l}\text { Sensitivity } \\
(\%)\end{array}$} & \multirow{2}{*}{$\begin{array}{l}\text { Specificity } \\
(\%)\end{array}$} \\
\hline & Value & $95 \%$ C & & & & & \\
\hline $\mathrm{OB} / \mathrm{T}$ volumetry & $0.891+$ & $0.779-0.958$ & $<.0001$ & 0.75 & $\leq 0.054 \mathrm{~cm}^{3}$ & 78.6 & 96.4 \\
\hline FA value & 0.683 & $0.545-0.801$ & 0.0124 & 0.3929 & $\leq 0.357$ & 57.1 & 82.1 \\
\hline ADC value & 0.708 & $0.571-0.822$ & 0.0039 & 0.429 & $\geq 1.417\left(\times 10^{-3} \mathrm{~mm}^{2} / \mathrm{s}\right)$ & 46.4 & 96.4 \\
\hline
\end{tabular}

Versus AUC $=0.5$ (DeLong method)

$A \cup C$ area under the ROC curve

†Statistically significant difference versus FA value ( $p$ value $=0.0008)$ and ADC value ( $p$ value $=0.0131$; DeLong method)

in which decreased inputs from the olfactory epithelium resulted in reduction of $\mathrm{OB} / \mathrm{T}$ volume [30-33].

DTI is a non-invasive imaging technique that analyzes the diffusion of water molecules within the tissues. The size, arrangement, and myelination of the axons of the white matter of the brain influence the diffusion of water molecules within them. Fractional anisotropy (FA) reflects the diffusion in various directions while ADC reflects the whole diffusion of water molecules, so an intact white matter tract has higher FA and lower ADC values than a structurally disturbed one (Fig. 1b) [34].

In this study, we integrate 3D DRIVE sequences and DTI to evaluate the effect of olfactory deprivation caused by sinonasal polyposis on $\mathrm{OB} / \mathrm{T}$ volume and integrity.

In many studies, age proved to be the strongest correlate of smell disorder in healthy persons, having a larger impact than cigarette smoking. Although marked individual differences are present, age-related smell disorder is more severe in men than women $[10,19,29]$. We could not find a correlation between age, sex, and smoking with $\mathrm{OB} / \mathrm{T}$ volume, FA, and $\mathrm{ADC}$ values in our study. This may be attributed to the small sample of patients, small number of female patients, and small numbers of smokers in the study. Future studies with large representative samples are required to further study the effect of these factors.

We did not perform olfactory tests in this study because our patients had nasal obstruction which led to decreased delivery of particles to the olfactory area. Also, we tried to omit the subjective factors in the study.

In our study, the difference in $\mathrm{OB} / \mathrm{T}$ volume between patient and control groups was highly statistically significant $(p<0.001)$. This was in accordance with Islam et al. [4] who reported that there is a significant reduction in $\mathrm{OB}$ volume in patients with bilateral sinonasal polyposis when compared with healthy controls. This result supports the findings in experimental animals, in which decreased inputs from the olfactory epithelium lead to reduction of $\mathrm{OB}$ volume [17, 30]. Also, Veyseller et al. [33] reported that diminished OB volume in total laryngectomy patients may be due to the inability to sniff normally, the lack of naso-pulmonary airflow, and complex neural interruptions caused by surgical denervation of the larynx.

Rombaux et al. [35] found that patients with posttraumatic or post-infectious olfactory loss have smaller OB volume which correlates with poorer recovery of olfactory function. Hence, $\mathrm{OB} / \mathrm{T}$ volume reduction may not only impair the sense of smell in sinonasal polyposis patients but may also be responsible of hindering olfactory recovery post operatively. On the other hand, Gudziol et al. [36] reported that the OT volume in patients with chronic rhinosinusitis had increased significantly after 3 months of medical treatment.

Another study found a positive correlation between olfactory deficit and the reduction in OT volume both in patients with Parkinson's disease (PD) and controls [37] which is contrary to what Hummel et al., Huissman et al., and Wattendorf et al. [38-40] concluded in their study where little or no difference was found between PD patients with anosmia/hyposmia and healthy controls in terms of OT volume.

Similarly, there were statistically significant differences in FA and ADC values between patients with sinonasal polyps and control group ( $p$ values 0.2114 and 0.00438 , respectively). Also, by using cutoff criterion $\leq 0.05 \mathrm{~cm}^{3}$, $\leq 0.35$, and $\geq 1.417\left(\times 10^{-3} \mathrm{~mm}^{2} / \mathrm{s}\right)$ for $\mathrm{OB} / \mathrm{T}$ volume,

Table $2 \mathrm{OB} / \mathrm{T}$ volume, FA value, and ADC value in cases and controls

\begin{tabular}{llll}
\hline Variable & Cases & Controls & $p$ value \\
\hline Olfactory bulb volume $\left(\mathrm{cm}^{3}\right)$ & $0.039(0.0235-0.05025)$ & $0.16(0.09325-0.25125)$ & $<0.001$ \\
FA value & $0.3495(0.27425-0.423)$ & $0.3865(0.35775-0.40225)$ & 0.02144 \\
ADC value $\left(\times 10^{-3} \mathrm{~mm}^{2} / \mathrm{s}\right)$ & $1.414(0.98725-1.63)$ & $1.0595(0.86925-1.299)$ & 0.00438 \\
\hline
\end{tabular}

Data are medians (interquartile range). Wilcoxon rank sum test. 


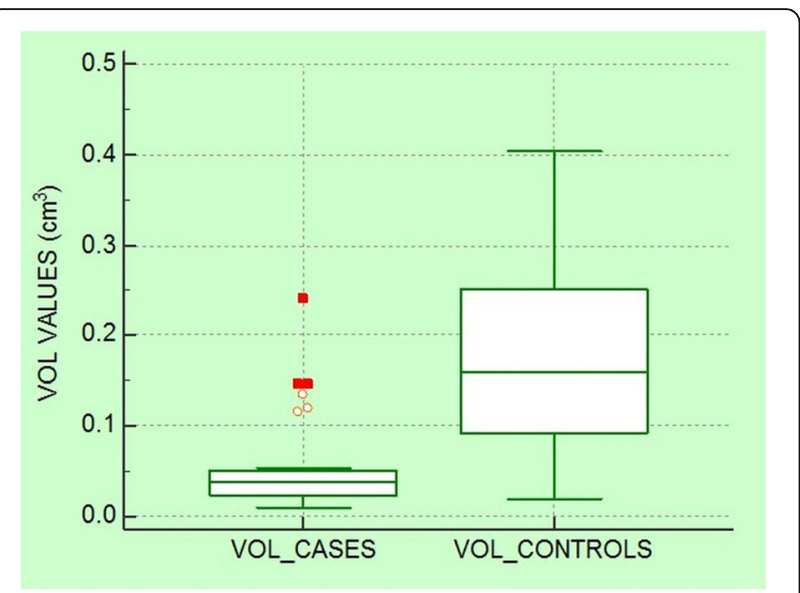

Fig 4 Box plot showing the olfactory bulb and tract volume in cases and controls

FA, and ADC values, respectively, discrimination between cases and controls could be obtained.

There were several studies that pointed out the capability of the analysis of the ADC and FA computed from DTI to reveal brain tissue damage in early clinical stages of neurodegenerative diseases, particularly PD. These studies found that PD patients could be completely differentiated from the control group based on reduced FA values $[26,40,41]$.

Previous studies suggested that head trauma is the most common cause of olfactory dysfunction, accounting for approximately $17 \%$ of all cases. Complete anosmia occurs in $5-10 \%$ of all head traumas, while an element of olfactory dysfunction in $20-44 \%$ of mild traumatic brain injury (TBIs) and $49-56 \%$ of moderate to severe TBIs. Of these cases, only $30-40 \%$ achieve partial recovery. DTI was used to furnish physical evidence of post-traumatic anosmia. It revealed dis-integrity of olfactory tracts [42-44].

The clinical value of imaging in patients with olfactory dysfunction has been controversial. Busaba [45] concluded that imaging was not needed in a patient with isolated olfactory dysfunction if clinical examination was normal. Mueller et al. [10], however, concluded that computed tomography (CT) scans are useful to diagnose conductive/inflammatory olfactory dysfunction in patients suspected of non-sinonasal disease. Imaging studies of the brain and paranasal sinuses are often obtained to determine the site and nature of the underlying pathology. Sinonasal CT is the technique of choice for the study of sinonasal structures [46].

Our study was the first to address the use of DTI as an objective measure of olfactory dysfunction in patients with nasal polyps. In the absence of obvious physical derangement, the diagnosis of olfactory dysfunction relied upon the patients' subjective reports. DTI can differentiate hyposmic/anosmic patients from controls and has shown to be useful in the evaluation of the central causes of an olfactory dysfunction.

The potential of this methodology thrilled the DTI community; however, it is critical to note that there is no established gold standard to assess the measurement limits and errors in DTI to confirm that the DTI interpretation is correct. So, introduction of several innovative readout strategies will provide better quality of DTI images and results.

There are few limitations in performing DTI of the olfactory region that need to be kept in mind such as susceptibility artifacts, which result from air spaces within sinonasal spaces or dental fillings with metallic materials. Due to the small number of patients, larger studies in different centers are required to confirm the results. Quantitative olfactory tests are recommended to study the correlation between subjective olfactory derangement and objective quantitative measurements. Also, study of the OB/T volumes and DTI parameters in patients with chronic sinonasal polyposis who underwent surgery to correlate between the subsequent expected increase in volume and recovery of olfactory tract integrity would be interesting to study.

$\mathrm{OB} / \mathrm{T}$ volumetry and DTI (FA and ADC) could be used as objective measurements to evaluate olfactory dysfunction in patients with sinonasal polyposis.

\section{Conclusions}

In this study, we conclude the following:

- Patients with sinonasal polyposis have a high prevalence of olfactory disorders.

- DTI parameters could be used as an objective method to evaluate olfactory tract integrity in patients with sinonasal polyposis.

- Decreased olfactory bulb and tract volume is significantly correlated with decreased olfactory sensitivity.

\section{Abbreviations}

ADC: Apparent diffusion coefficient; DTI: Diffusion tensor imaging; FA: Fractional anisotropy; OB/T: Olfactory bulb and tract; PD: Parkinson's disease

\section{Acknowledgements}

Not applicable

\section{Authors' contributions}

$\Pi \pi$ was the guarantor of integrity of the entire study and did the study concepts and design, evaluation of patients' MRI studies and manuscript preparation. AM did literature research, post processing of the DTI and volumetry studies. MST did the clinical studies and manuscript editing. HM,TMR, and AMA did the clinical studies. All authors have read and approved the manuscript.

Funding

This study had no funding from any resource. 


\section{Availability of data and materials}

The data sets used and/or analyzed during the current study are available from the corresponding author on reasonable request.

\section{Ethics approval and consent to participate}

The study was approved by the institutional ethical committee (Faculty of Medicine, Ain Shams University Ethical Committee), the committee's reference number is not applicable. The informed consent obtained from study participants was verbal as all the procedures are noninvasive, so written consent was not required by the institutional ethical committee.

\section{Consent for publication}

All patients included in this research gave written informed consent to publish the data contained within the study. If the patient was less than 16 years old, deceased, or unconscious when consent for publication was requested, written informed consent for the publication of this data was given by the parents or legal guardian.

\section{Competing interests}

The authors declare that they have no competing interests.

\section{Author details}

${ }^{1}$ Department of Radiology, Ain Shams University, Cairo, Egypt. ${ }^{2}$ Department of Otorhinolaryngology, Ain Shams University, Cairo, Egypt.

Received: 10 December 2019 Accepted: 21 January 2020

\section{Published online: 20 February 2020}

\section{References}

1. Wilson RS, Schneider JA, Arnold SE, Tang Y, Boyle PA, Bennett DA (2007) Olfactory identification and incidence of mild cognitive impairment in older age. Arch Gen Psychiatry 64:802-808

2. Brämerson A, Johansson L, Ek L et al (2004) Prevalence of olfactory dysfunction: The Skövde population-based study. Laryngoscope 114(4):733737

3. Murphy C, Schubert CR, Cruickshanks KJ et al (2002) Prevalence of olfactory impairment in older adults. JAMA 288(18):2307-2312

4. Herzallah IR, Askar MD, Amer HS, Ahmed AF, El-Anwar MW, Eesa MH (2013) Olfactory bulb volume changes in patients with sinonasal polyposis. Otolaryngology Head and Neck Surgery 148(4):689-693

5. Raviv JR, Kern RC (2004) Chronic sinusitis and olfactory dysfunction. Otolaryngol Clin North Am 37:1143-1157

6. Seiden AM, Duncan HJ (2001) The diagnosis of a conductive olfactory loss. Laryngoscope 111:9-14

7. Rombaux P, Huart C, Deggouj N, Duprez T, Hummel T (2012) Prognostic value of olfactory bulb volume measurement for recovery in postinfectious and posttraumatic olfactory loss. Otolaryngol Head Neck Surg 147:11361141

8. Lin A, Ross BD, Harris K et al (2005) Efficacy of proton magnetic resonance spectroscopy in neurological diagnosis and neurotherapic decision making. NeuroRx 2(2):197-214

9. Wrobel BB, Leopold DA (2004) Clinical assessment of patients with smell and taste disorders. Otolaryngol Clin North Am 37(6):1127-1142

10. Mueller C, Temmel AF, Toth J et al (2006) Computed tomography scans in the evaluation of patients with olfactory dysfunction. Am J Rhinol 20(1): 109-112

11. Ikeda K, Sakurada T, Suzaki Y, Takasaka T (1995) Efficacy of systemic corticosteroid treatment for anosmia with nasal and paranasal sinus disease. Rhinology 33(3):162-165

12. Wolfensberger $M$, Hummel $T$ (2002) Anti-inflammatory and surgical therapy of olfactory disorders related to sino-nasal disease. Chem Senses 27(7):617622

13. Nicoletti G, Tonon C, Lodi R et al (2008) Apparent diffusion coefficient of the superior cerebellar peduncle differentiates progressive supranuclear palsy from Parkinson's disease. Movement Disord 23(16):2370-2376

14. Ibarretxe-Bilbao N, Zarei M, Junque C et al (2011) Dysfunction of cerebra networks precede recognition memory deficits in early Parkinson's disease. Neuroimage 57(2):589-597

15. Welge-Lüssen A, Wattendorf E, Schwerdtfeger $U$ et al (2009) Olfactory induced brain activity in Parkinson's disease relates to the expression of event-related potentials-an fMRI study. Neuroscience 162(2):537-543
16. Westermann B, Wattendorf E, Schwerdtfeger U et al (2008) Functional imaging of the cerebral olfactory system in patients with Parkinson's disease. J Neurol Neurosurg Psychiatry 79(1):19-24

17. Ibarretxe-Bilbao N, Junque C, Marti MJ et al (2010) Olfactory impairment in Parkinson's disease and white matter abnormalities in central olfactory areas: a voxel-based diffusion tensor imaging study. Mov Disord 25(12): 1888-1894

18. Holbrook EH, Leopold DA (2003) Anosmia: diagnosis and management. Current opinion in otolaryngology \& head and neck surgery 11(1):54-60

19. Hummel T, Smitka M, Puschmann S, Gerber JC, Schaal B, Buschhüter D (2011) Correlation between olfactory bulb volume and olfactory function in children and adolescents. Exp Brain Res 214:285-291

20. Haehner A, Rodewald A, Gerber JC, Hummel T (2008) Correlation of olfactory function with changes in the volume of the human olfactory bulb. Arch Otolaryngol Head Neck Surg. 134:621-624

21. Rombaux P, Duprez T, Hummel T (2009) Olfactory bulb volume in the clinical assessment of olfactory dysfunction. Rhinology 47(1):3-9

22. Skorpil M, Rolheiser T, Robertson H, Sundin A, Svenningsson P (2011) Diffusion tensor fiber tractography of the olfactory tract. Magnetic resonance imaging 29(2):289-292

23. Torresa CV, Manzanaresb R, Solac RG (2014) Integrating diffusion tensor imaging-based tractography into deep brain stimulation surgery: a review of the literature. Stereotact Funct Neurosurg 92:282-290. https://doi.org/10. 1159/000362937

24. Milardi D, Cacciola A, Calamuneri A et al (2017) The olfactory system revealed non-invasive mapping by using constrained spherical deconvolution tractography in healthy humans. Front. Neuroanat 11:32. https://doi.org/10.3389/fnana.2017.00032

25. Tessa C, Giannelli M, Della Nave R et al (2008) A whole-brain analysis in de novo Parkinson disease. AJNR 29(4):674-680

26. Le Bihan D (2003) Looking into the functional architecture of the brain with diffusion MRI. Nature Rev Neurosc 4(6):469-480

27. Schocke MF, Seppi K, Esterhammer R et al (2004) Trace of diffusion tensor differentiates the Parkinson variant of multiple system atrophy and Parkinson's disease. Neuroimage 21(4):1443-1451

28. Hagmann P, Jonasson L, Maeder P, Thiran JP, Wedeen VJ, Meuli R (2006) Understanding diffusion MR imaging techniques: from scalar diffusionweighted imaging to diffusion tensor imaging and beyond. Radiographics 26(Suppl 1):S205-U219

29. Doty RL, Shaman P, Dann M (1984) Development of the University of Pennsylvania Smell Identification Test: a standardized microencapsulated test of olfactory function. Physiol Behav 32:489-502

30. Ackerstaf AH, Hilgers FJM, Aarson NK, Balm AJM (1994) Communication, functional disorders and lifestyle changes after total laryngectomy. Clin Otolaryngol 19:295-300

31. Cummings DM, Knab BR, Brunjes PC (1997) Effects of unilateral olfactory deprivation in the developing opossum, Monodelphis domestica. J Neurobiol 33:429-438

32. Mandairon N, Sacquet J, Jourdan F, Didier A (2006) Long-term fate and distribution of newborn cells in the adult mouse olfactory bulb: influences of olfactory deprivation. Neuroscience 141:443-451

33. Veyseller B, Aksoy F, Yildirim YS et al (2011) Reduced olfactory bulb volume in total laryngectomy patients: a magnetic resonance imaging study. Rhinology 49:112-116

34. Skorpil M, Rolheiser T, Robertson H, Sundin A, Svenningsson P (2010) Diffusion tensor fiber tractography of the olfactory tract. Magn Reson Imaging 29:289-292. https://doi.org/10.1016/j.mri.2010.07.004

35. Rombaux P, Potier H, Bertrand B, Duprez T, Hummel T (2008) Olfactory bulb volume in patients with sinonasal disease. Am J Rhinol. 22:598-601

36. Gudziol V, Buschhüter D, Abolmaali N, Gerber J, Rombaux P, Hummel T (2009) Increasing olfactory bulb volume due to treatment of chronic rhinosinusitis: a longitudinal study. Brain 132:3096-3101

37. Wang J, You H, Liu JF, Zhang ZX, Guan J (2011) Association of olfactory bulb volume and olfactory sulcus depth with olfactory function in patients with Parkinson disease. AJNR 32(4):677-681

38. Hummel T, Witt M, Reichmann H et al (2010) Immunohistochemical, volumetric, and functional neuroimaging studies in patients with idiopathic Parkinson's disease. J Neurological Sci 298(1-2):119-122

39. Huisman E, Uylings HB, Hoogland PV (2004) A 100\% increase of dopaminergic cells in the olfactory bulb may explain hyposmia in Parkinson's disease. Mov Disord. 19(6):687-692 
40. Wattendorf E, Welge-Lüssen A, Fiedler K et al (2009) Olfactory impairment predicts brain atrophy in Parkinson's disease. J Neurosci. 29(9):15410-15413

41. Karagulle Kendi AT, Lehericy S, Luciana M, Ugurbil K, Tuite P (2008) Altered diffusion in the frontal lobe in Parkinson disease. AJNR 38(3):501-505

42. Yousem DM, Geckle RJ, Bilker WB, Kroger H, Doty RL (1999) Posttraumatic smell loss: relationship of psychophysical tests and volumes of the olfactory bulbs and tracts and the temporal lobes. Academic radiology 6(5):264-272

43. Schofield PW, Moore TM, Gardner A (2014) Traumatic brain injury and olfaction: a systematic review. Front neurol 5:5

44. Doty RL, Yousem DM, Pham LT, Kreshak AA, Geckle R, Lee WW (1997) Olfactory dysfunction in patients with head trauma. Archives of Neurology 54(9):1131-1140

45. Busaba NY (2001) Is imaging necessary in the evaluation of the patient with an isolated complaint of anosmia? Ear Nose Throat J 80(12):892-896

46. Li C, Yousem DM, Doty RL, Kennedy DW (1994) Neuroimaging in patients with olfactory dysfunction. Am J Roentgenol 162:411-418

\section{Publisher's Note}

Springer Nature remains neutral with regard to jurisdictional claims in published maps and institutional affiliations.

\section{Submit your manuscript to a SpringerOpen ${ }^{\circ}$ journal and benefit from:}

- Convenient online submission

- Rigorous peer review

- Open access: articles freely available online

- High visibility within the field

- Retaining the copyright to your article 